\title{
Encefalites autoimunes - abordagem prática para situações de recursos limitados
}

\author{
Christian Pereira Gregory', Adaucto Wanderley da Nóbrega Junior ${ }^{2}$, Katia Lin ${ }^{3}$
}

1. Acadêmico do Curso de Graduação em Medicina, Centro de Ciências da Saúde, Universidade Federal de Santa Catarina

2. Médico neurologista, Hospital Universitário Prof. Polydoro Ernani de São Thiago, Universidade Federal de Santa Catarina

3. Professora do Departamento de Clínica Médica, Centro de Ciências da Saúde, Universidade Federal de Santa Catarina

Indexadores: encefalite; encefalite autoimune; autoimunidade Submetido em 17/03/2019. Aprovado para publicação em 17/05/2019

Autor para correspondência: Christian Pereira Gregory (chrispgregory@gmail.com)

\begin{abstract}
RESUMO
As encefalites autoimunes são um grupo de doenças causadas por autoanticorpos contra antígenos neuronais. Nos últimos dez anos, surgiram várias publicações que possibilitaram classificar e tratar pacientes com quadros de encefalites que antes eram irreconhecíveis e fatais. Estima-se que as causas autoimunes são responsáveis por 20\% de todas as encefalites. Pelo fato de o diagnóstico ser bastante dependente de testes imunológicos de difícil acesso no SUS, este trabalho apresenta uma revisão não sistemática, com o enfoque em uma abordagem clínica dessas doenças, de modo prático, que agilize o diagnóstico destas emergências neurológicas, mesmo em locais de recursos limitados. A pesquisa da literatura foi baseada na base de dados do PubMed, Medline.
\end{abstract}

DOI: https://doi.org/10.32963/bcmufsc.v5i2.3488

\section{INTRODUÇÃO}

As encefalites autoimunes são um grupo de doenças inflamatórias do parênquima cerebral causadas pela produção de autoanticorpos contra antígenos neuronais ${ }^{1}$. Esse grupo de doenças ganhou destaque nos últimos dez anos, a partir de publicações que descreveram várias síndromes neurológicas e as associaram com seus respectivos autoanticorpos, possibilitando classificar e tratar pacientes cujos quadros clínicos eram antes irreconhecíveis e fatais ${ }^{2}$. Embora não sejam tão prevalentes quanto as de causa infecciosa, estima-se que as causas autoimunes correspondem a $20 \%$ de todas as encefalites no norte da Europa ${ }^{3}$. Atualmente, os critérios diagnósticos dessas doenças são bastante dependentes de testes de autoanticorpos, porém são exames caros, demorados ${ }^{2}$ e pouco disponibilizados nos centros brasileiros, sendo portanto doenças de difícil manejo na realidade brasileira ${ }^{4}$. As encefalites autoimunes são emergências neurológicas ${ }^{5}$, portanto esse trabalho busca revisar uma abordagem que permita a investigação e o tratamento inicial mesmo na ausência dos testes de autoanticorpos ou enquanto se aguarda o resultado dos mesmos, com o fim de se obter um melhor prognóstico ${ }^{6}$.

\section{MÉTODOS}

A pesquisa da literatura médica e os critérios de seleção foram baseados na busca através da base de dados do PubMed,
Medline, por publicações dos últimos 10 anos - de agosto de 2008 a agosto de 2018, escritos em inglês, através do termo "autoimmune encephalitis". Os artigos foram selecionados para esta revisão pela sua qualidade, originalidade e relevância para 0 assunto. As citações relevantes que foram identificadas nesses artigos e que não apareceram na pesquisa inicial também foram incluídas.

\section{REVISÃO}

\subsection{Visão geral sobre as encefalites autoimunes}

As encefalites autoimunes são um grupo de doenças cuja causa e/ou epifenômeno são a produção de anticorpos de vários tipos que atacam o parênquima cerebral -especificamente: (1) os antígenos da superfície celular neuronal, (2) os antígenos sinápticos, e (3) os antígenos intraneuronais que também são chamados de onconeurais ${ }^{1}$. 0 primeiro tipo se liga às moléculas neuronais envolvidas na neurotransmissão levando à disfunção neuronal (através de alterações dos canais iônicos ou receptores), o segundo interfere na liberação dos neurotransmissores e o último tipo é indiretamente patogênico pois atua através da resposta Timunomediada ${ }^{1,7}$. Sugere-se que os mecanismos que as deflagram sejam infecções (parainfecciosas), criptogênicos ou um câncer subjacente (paraneoplásicas) ${ }^{8}$, podendo ocorrer num mesmo paciente a coexistência de dois ou mais autoanticorpos ${ }^{1}$. 


\section{Quadro 1 - Os passos na investigação das encefalites autoimunes}

1. Anamnese e exame físico com exame neurológico minucioso, questionando por viagens prévias, exposição a doenças infectocontagiosas, abuso de álcool ou drogas, uso de medicamentos, história mórbida pregressa incluindo doenças neurológicas e cânceres. Considere solicitar inicialmente os seguintes exames: RM, EEG, PL (incluir lactato, culturas, esfregaço para BAAR, PCR para HSV 1/2, HHV6, EBV, CMV e enterovírus; HIV RNA, VDRL, Anticorpos para Lyme e arbovirus, PCR para T. whipplei, proteína 14-3-3 e tau), sorologias ( HIV 1/2, Lyme), exames toxicológicos do sangue e urina, lactato sérico, carboxiemoglobina, ANCA, crioglobulinas, anticorpos antifosfolipídeos, exames de imagem vascular e demais exames dos quais o médico julgue necessário para excluir outras causas.

2. Avaliar se o quadro clínico do paciente se enquadra em um caso de possível encefalite autoimune através dos critérios abaixo (quadro 2) e excluir outras possíveis causas (apêndice 1)

3. Classificar a encefalite com os critérios das síndromes reconhecíveis de encefalites autoimunes (apêndice 2)

4. Se possível, fazer titulação dos anticorpos do sangue e do líquor antes do tratamento

5. Iniciar tratamento assim que possível, e considerando a possibilidade de um tumor subjacente e o resultado dos autoanticorpos se disponível

FONTE: Próprio autor.

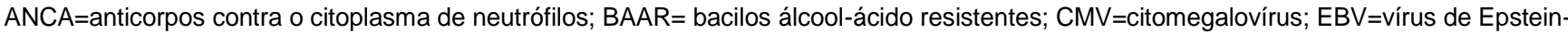

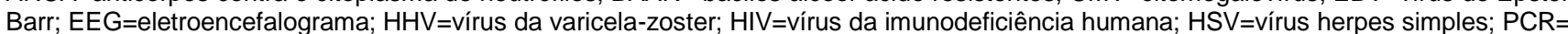
reação em cadeia da polimerase; $\mathrm{PL}=$ punção lombar; $\mathrm{RM}=$ ressonância magnética; $\mathrm{RNA}=$ ácido ribonucleico; $\mathrm{VDRL}=$ Venereal Disease Research Laboratory

0 quadro 1 resume os passos da investigação e os principais exames iniciais a serem pedidos. Durante a investigação, dividiremos os quadros suspeitos de encefalite autoimune conforme a chance do diagnóstico ser real, usando 3 categorias: casos possíveis e prováveis- nas quais raramente se necessita dos testes de autoanticorpos, e casos definitivos - nas quais mais frequentemente se necessita desses testes. Esses níveis de evidência clínica são os mesmos propostos por Graus et al?

\section{Quadro 2 - critérios diagnósticos para possível encefalite autoimune}

O diagnóstico de uma possível encefalite autoimune precisa contemplar os 3 itens abaixo:

1. Início subagudo (de rápida progressão e em menos de 3 meses) de: déficits de memória de trabalho* (perda da memória de curto prazo), ou de alteração do estado mental $\dagger$, ou de sintomas psiquiátricos

2. Pelo menos um dos seguintes:

- Novos achados neurológicos focais

- $\quad$ Crises epilépticas não explicadas por uma doença anterior conhecida

- Pleocitose no LCR (leucócitos >5células $/ \mathrm{mm} 3$ )

- RM com achados sugestivos de encefaliteł

3. Exclusão adequada das causas alternativas

* Déficit de memória é definido como um problema em formar novas memórias de longo prazo por algum acometimento hipocampal ou da memória de trabalho, que são estruturas envolvidas na manipulação e no armazenamento temporário da memória

† Alteração no estado mental é definida como diminuição ou alteração do nível de consciência, letargia ou alteração de personalidade. ¥ Sinal hiperintenso em sequências de T2-FLAIR altamente restritas a um ou ambos os lobos temporais mediais (encefalite límbica), ou em áreas multifocais envolvendo substância cinzenta, branca, ou ambas, compatível com desmielinização ou inflamação

FONTE: Adaptado de Graus et al, $2016^{2}$

LCR=líquido cefalorraquidiano; RM=ressonância magnética; T2-FLAIR= imagens de recuperação de inversão atenuada por fluidos em T2

\section{2}

\author{
Quando suspeitar de uma possível encefalite \\ autoimune? \\ Os critérios para iniciar a investigação (quadro 2)
} classificam os quadros suspeitos como possível encefalite autoimune. É imprescindível excluir outras causas que expliquem 0 quadro (apêndice 1), principalmente as infecciosas, já que 0 tratamento com imunossupressão pode agravar esses casos². Os exames de PL, RM e EEG são úteis no diagnóstico diferencial e muitas vezes trazem resultados normais ou inespecíficos - o que não impede a investigação de prosseguir ${ }^{\text {. }}$.
3.3 As síndromes reconhecíveis das encefalites autoimunes e suas manifestações

Após contemplarem os critérios de possível encefalite autoimune (quadro 2), os pacientes podem ser classificados dentro de algumas síndromes que ajudam a determinar qual é 0 autoanticorpo mais provável por causar a doença. Para isso, foram criados critérios por Graus et al2 que possibilitam o diagnóstico definitivo de encefalite autoimune sem os testes de autoanticorpos. Essas síndromes reconhecíveis se dividem em²:

1. Encefalite límbica autoimune;

2. Encefalomielite aguda disseminada e outras síndromes com desmielinização na RM; 
3. Encefalite anti-NMDAr;

4. Encefalite do tronco cerebral de Bickerstaff.

0 apêndice 2 descreve cada uma dessas síndromes quanto aos seus critérios diagnósticos, manifestações, anticorpos prováveis e exames complementares. Essa classificação inclui 0 item 2 pela similaridade do quadro clínico às outras encefalites autoimunes. Dentre elas, a anti-NMDAr é uma das mais comuns e estudadas, em parte por haver um quadro clínico bem caracterizado ${ }^{4}$. Os pacientes que não se enquadram em nenhuma síndrome serão discutidos na seção 8.

As manifestações da encefalite autoimune são variadas e incluem distúrbios do movimento, autonômicos, gastrointestinais e distúrbios do sono. As manifestações mais comuns são crises epilépticas dos mais diversos tipos, inclusive status epilepticus refratário ${ }^{11}$. No geral o quadro lembra uma encefalite do tipo infecciosa ${ }^{9}$, podendo o sexo e a idade do paciente serem importantes para caracterizar o autoanticorpo responsável ${ }^{2}$. Nas crianças, atentar-se que os critérios diagnósticos de encefalite autoimune são baseados em adultos, pela escassez na literatura. Nos idosos, a avaliação clínica pode ser dificultada pelas próprias limitações do paciente, pelas alterações da senilidade na cognição e na memória, ou por outras doenças pré-existentes ${ }^{2}$.Vale lembrar que, embora crises epilépticas estejam associadas em algumas encefalites autoimunes, é controverso se autoanticorpos sejam a etiologia ou mais um epifenômeno das mais diversas síndromes epilépticas ${ }^{12}$.

\subsection{Exames complementares}

Ressonância Magnética

A Ressonância Magnética do encéfalo não é um exame sensível nem específico nas encefalites autoimunes e pode mostrar achados normais ou inespecíficos, principalmente no início do quadro ${ }^{2}$. Porém, seu resultado pode excluir várias etiologias alternativas e conter detalhes altamente sugestivos para determinadas síndromes clínicas. 0 realce pelo meio do contraste é variável e os padrões típicos são hipersinal no FLAIR ou T2 das regiões afetadas do cérebro, como os lobos temporais mediais e/ou tronco cerebral, podendo também ter achados nas regiões subcorticais e no cerebelo $2,4,18$.

Eletroencefalograma

As alterações do EEG nas encefalites autoimunes são pouco específicas, exceto na encefalite anti-NMDAr em que cerca de um terço dos pacientes apresentam um padrão característico chamado extremo delta brush ${ }^{19}$. É importante usar o EEG para excluir o estado de mal epiléptico não convulsivo. Dentre os padrões inespecíficos mais comuns, estão a atividades epileptiformes (lentas, focais ou generalizadas) e as descargas epileptiformes periódicas lateralizadas (conhecidas por PLEDS) 20,21

\section{Punção Lombar}

$\mathrm{Na}$ investigação do LCR pela punção lombar, deve-se avaliar a contagem de células, proteína e glicose, excluir etiologias infecciosas e metastáticas. Os resultados podem ser normais ou levemente alterados, e achados inflamatórios não são regra, principalmente em idosos. As alterações mais comuns são a elevação das proteínas, presença de bandas oligoclonais, pleocitose linfocítica leve a moderada e índice de lgG elevado 2,4,21. Testes de autoanticorpos

Antes de discutir a investigação dos anticorpos, é importante entender alguns conceitos a partir da diferença entre epítopos lineares e conformacionais, explicada abaixo.

Epítopos lineares: antígenos de estrutura proteica primária que não são afetados pela desnaturação das proteínas 22 . Os anticorpos desses epítopos são os onconeurais e os anti-GAD, cujo alvo são proteínas intracelulares e estão presentes no soro e no LCR. O resultado sérico é fidedigno e, por não serem afetados pela desnaturação, várias técnicas podem ser usadas para detectálos, incluindo ELISA, immunoblotting e imunohistoquímica $2,7,23$.

Epítopos conformacionais: antígenos que são formados por estruturas proteicas secundárias, terciárias e quaternárias que, quando desnaturadas, não mais são reconhecidos pelos anticorpos $^{22}$. Compõem a maioria dos autoanticorpos das encefalites autoimunes, especialmente os contra superfície neuronal, logo necessitam de técnicas de detecção mais complexas em que os antígenos possuem sua conformação original ${ }^{1,2}$. Essas técnicas são: (1) ensaio baseado em células HEK293 (cell-based assay, CBA), altamente sensível e portanto a primeira a ser solicitada, podendo no entanto apresentar falsos-positivos e falsosnegativos nas dosagens séricas; (2) ensaio baseado em tecidos (TBA) cerebrais de roedores usando imunohistoquímica ou imunofluorescência indireta, eficaz para rastreio por detectar a maioria dos anticorpos conhecidos e inclusive revelar novos anticorpos, como também para quando houver dúvida no CBA; e (3) cultura de neurônios hipocampais dissociados de ratos, realizada geralmente em laboratórios de pesquisa e é útil para confirmação quando os dois primeiros testes apresentam resultados conflitantes ${ }^{4,21}$

O alvo dos autoanticorpos possui uma subunidade específica para manifestar os sintomas. Como exemplo, os receptores NMDA são afetados na sua subunidade GluN1 para que ocorra a encefalite anti-NMDAr, enquanto que anticorpos contra as subunidades GluN2/3 possuem significado clínico desconhecido. Já o complexo proteico do receptor de potássio voltagem-dependente (VGKC) está envolvido na encefalite autoimune quando existem anticorpos contra os epítopos LGI1 e CASPR2 desse complexo, sendo cada um deles associado a quadro clínico diferente ${ }^{2}$.

Os autoanticorpos investigados são os $\lg \mathrm{G}$ e a detecção de $\lg \mathrm{A}$ ou $\lg \mathrm{M}$ possuem significado incerto, por estarem presentes em outras doenças e também em uma proporção de pessoas saudáveis ${ }^{24}$. Alguns princípios devem ser seguidos durante a investigação e análise dos resultados 2,24:

1. Investigue os anticorpos no sangue e LCR simultaneamente $A$ prática de testar o LCR apenas se o teste sérico vier negativo não é adequada pois: (1) Atrasa o diagnóstico; (2) Em muitos casos os autoanticorpos relevantes encontram-se apenas no LCR ; (3) Havendo autoanticorpos discordantes no soro e no LCR (NMDAr no LCR e GABA-Ar no soro, por exemplo), o que determina o quadro clínico é o que está presente no $\operatorname{LCR}^{1,2,4,25}$.

2. Considere o teste como falso-positivo se o quadro clínico não se enquadra ao anticorpo identificado, ou se os testes séricos forem positivos, mas o LCR der negativo - apenas em raros casos estarão presentes apenas no soro (como o anti-LGI1). Contate o laboratório e repita o teste, ou faça testes confirmatórios (imunohistoquímica cerebral ou cultura neuronal) 4,14

3. A avaliação clínica é soberana aos testes de autoanticorpos ao decidir a conduta, já que a correlação do quadro e dos exames não é perfeita e os títulos dos anticorpos geralmente são detectáveis mesmo após a melhora do quadro. Erros inerentes à técnica e uso de corticoesteroides também podem resultar em falsos-negativos ${ }^{1,2,4}$.

4. Nem todos os autoanticorpos possuem testes disponíveis e alguns deles ainda precisam ser descobertos, portanto resultados negativos não excluem a hipótese².

No Brasil, testes comerciais de CBA e TBA não são aprovados pelos órgãos nacionais, portanto as amostras geralmente são enviadas a laboratórios de pesquisa para que sejam usados outros métodos ${ }^{4}$. Os testes dos autoanticorpos superam a significância clínica da biópsia cerebral, o qual sugere um processo inflamatório, porém não pode ser usado para estabelecer a etiologia autoimune? ${ }^{2}$.

Em suma, sugere-se a seguinte técnica para cada um dos autoanticorpos abaixo $2,21,23$ : 
- CBA: anti-NDMAr, anti-AMPAr, anti-GABA-Br, antiGABA-Ar, anti receptor D2 de dopamina, anti-LGI1, antiCASPR2, anti-DPPX, anti-MOG, anti-AQP-4, antiIgLON5, anti-Neurexina-3-alfa

- TBA: Anti-GFAP

- $\quad$ ELISA: anti-GQ1b, anti-GAD

- Radioimunoensaio: anti-GAD

\subsection{Abordagem Diagnóstica}

Abordagem dos pacientes que atendem os critérios das síndromes reconhecíveis

O diagnóstico das encefalites autoimunes se inicia a partir de um caso que se encaixa nos critérios de uma possível encefalite autoimune (quadro 2). Ao se identificar em um paciente alguma síndrome reconhecível (apêndice 2), o diagnóstico é feito e partese para iniciar o tratamento.

Em condições ideais, o teste de autoanticorpos específicos é solicitado para estabelecer o subtipo da encefalite, porém pode ser dispensado nos casos em que a investigação não deixa dúvidas. Mesmo assim, o autor salienta a importância de se enviar amostras desses pacientes em um segundo momento a um centro de referência, com o propósito de contribuir para pesquisas futuras. Abordagem dos pacientes que não atendem os critérios das síndromes reconhecíveis

Alguns pacientes que satisfazem os critérios do quadro 2 (de possível encefalite autoimune) não se enquadram nas síndromes bem caracterizadas da tabela 4. Quando isso ocorre, a anamnese detalhada pode dar pistas da causa base (por exemplo: teratoma sugere anti-NMDAr, crises epilépticas faciobraquiais distônicas sugerem anti-LGI1, diarreia sugere anti-DPPX) e os autoanticorpos terão uma grande importância para se definir 0 diagnóstico ${ }^{2}$. Existem três possibilidades para explicar esses casos $^{2}$ :

1. Síndrome não clássica de encefalite autoimune, porém com autoanticorpos detectáveis (encefalite autoimune definitiva)

2. Encefalopatia de Hashimoto (quadro 3)

3. Encefalite autoimune sem anticorpos detectáveis (quadro 4)

\section{Quadro 3 - Critérios diagnósticos para encefalopatia de Hashimoto (provável encefalite autoimune)}

O diagnóstico é feito ao atender todos os seis critérios abaixo:

1. Encefalopatia com crises epilépticas, mioclonia, alucinações ou episódios stroke-like

2. Tireoidopatia subclínica ou manifesta

3. RM cerebral normal ou com anormalidades

4. Presença de anticorpos séricos da tireoide (tireoperoxidase, tireoglobulina)*

5. Ausência de anticorpos bem caracterizados no soro ou LCR

6. Exclusão adequada de outras causas

* Não são anticorpos específicos da doença, podendo estar presentes em 13\% dos indivíduos saudáveis

FONTE: Adaptado de Graus et al, $2016^{2}$

LCR=líquido cefalorraquidiano; RM=ressonância magnética

Quadro 4 - Critérios para provável encefalite autoimune sem anticorpos detectáveis (provável encefalite autoimune)

O diagnóstico é feito ao atender todos os quatro critérios abaixo:

1. Progressão rápida (<3 meses) de déficits de memória de trabalho (perda de memória de curto prazo), alteração do estado mental, ou sintomas psiquiátricos

2. Exclusão das síndromes bem definidas de encefalite autoimune (acima)

3. Ausência de auto-anticorpos bem caracterizados no soro e no LCR e pelo menos 2 dos abaixo:

a. Anormalidades na RM sugestivas de encefalite autoimune *

b. LCR com pleocitose, bandas oligoclonais ou elevado índice lgG, ou ambos

c. Biópsia cerebral evidenciando infiltrados inflamatórios e excluindo outras doenças (ex: tumor)

4. Exclusão apropriada/adequada de causas alternativas

* Algumas doenças metabólicas e mitocondriais podem apresentar com anormalidades simétricas ou assimétricas na RM associadas a alterações inflamatórias, assemelhando-se a uma doença autoimune adquirida

FONTE: Adaptado de Graus et al, $2016^{2}$

IgG=imunoglobulina G; LCR=líquido cefalorraquidiano; RM=ressonância magnética 
A encefalopatia de Hashimoto (também chamada de encefalopatia responsiva a esteroides associada à tireoidite autoimune) é uma doença cuja fisiopatologia é pouco compreendida, possivelmente imunomediada pela boa resposta à terapia com esteroides. Acomete em geral mulheres de qualquer idade, com tireoidopatia franca ou subclínica, e se manifesta com encefalopatia, crises epilépticas, mioclonia, alucinações e episódios stroke-like com LCR e RM normais ou com alterações não-específicas. Anticorpos antitireoide e alfa-enolase costumam estar presentes, mas não são específicos para encefalopatia de Hashimoto e estão presentes em alguns indivíduos saudáveis ou com outras encefalites autoimunes ${ }^{26}$.

\section{Quadro 5 - Demais doenças que compõem o diagnóstico diferencial das encefalites autoimunes:}

\begin{tabular}{|c|c|}
\hline Doença / Síndrome & Observações \\
\hline $\begin{array}{ll} & \text { Síndrome de Morvan } \\
\text { - } & \text { Encefalite de Rasmussen }\end{array}$ & $\begin{array}{l}\text { São de clara etiologia autoimune, porém os sintomas iniciais (hiperexcitabilidade de } \\
\text { nervos periféricos, crises focais e déficits unilaterais) são diferentes dos típicos da } \\
\text { encefalite autoimune e o quadro clínico possui uma evolução mais lenta }{ }^{2} \text {. A } \\
\text { síndrome de Morvan está associada ao anticorpo anti-CASPR2 em } \\
\text { aproximadamente } 70 \% \text { dos casos, não sendo, porém, um marcador específico da } \\
\text { doença. }\end{array}$ \\
\hline - $\quad$ Status Epilepticus & $\begin{array}{l}\text { - RM com envolvimento bilateral dos lobos temporais mediais } \\
\text { - Características distintas: Mais comum em crianças e adultos jovens. RM com } \\
\text { anormalidades além dos lobos temporais } \\
\text { - Testes diagnósticos: EEG. Hipersinal na RM é reversível, sendo substituído } \\
\text { gradativamente por atrofia. }\end{array}$ \\
\hline - $\quad$ Síndrome de Kikuchi-Fujimoto & $\begin{array}{l}\text { - RM com envolvimento bilateral dos lobos temporais mediais } \\
\text { - LCR com pleocitose } \\
\text { - Características distintas: Adenopatia cervical, RM com anormalidades além dos } \\
\text { lobos temporais } \\
\text { - Testes diagnósticos: Biópsia de linfonodos demonstrando linfadenite histiocítica } \\
\text { necrotizante. }\end{array}$ \\
\hline - Doença linfoproliferativa ligada ao X & $\begin{array}{l}\text { - RM com envolvimento bilateral dos lobos temporais mediais } \\
\text { - LCR com pleocitose } \\
\text { - Características distintas: RM com anormalidades além dos lobos temporais } \\
\text { - Testes diagnósticos: Confirmação genética }\end{array}$ \\
\hline $\begin{array}{l}\text { - FIRES - febrile infection-related epilepsy } \\
\text { syndrome }\end{array}$ & $\begin{array}{l}\text { - Episódio febril inicial em crianças saudáveis seguido de crises epilépticas. Evoluem } \\
\text { rapidamente para status epilepticus, epilepsia farmacorresistente e deterioração } \\
\text { cognitiva. RM inicialmente normal, mas com atrofia bilateral temporal após alguns } \\
\text { meses. LCR sem pleocitose ou bandas oligoclonais. }\end{array}$ \\
\hline
\end{tabular}

FONTE: Adaptado de Graus et al, $2016^{2}$

CASPR2= proteína associada à contactina 2; EEG=Eletroencefalograma; LCR=líquido cefalorraquidiano; RM=ressonância magnética

Os pacientes que atendem aos critérios do quadro 4 fazem parte de um grupo de síndromes ainda não reconheciveis e de anticorpos não identificados. Nesses casos o auxílio de um centro de referência é importante para futuramente identificar novos anticorpos e síndromes. Nos casos que não satisfazem esses critérios ou nenhum dos outros supracitados, considera-se que a chance de ser uma doença autoimune é mais remota e deve-se buscar por outras causas (quadro 5) que expliquem o quadro².

\section{Diagnóstico de possíveis tumores associados ao quadro}

Alguns quadros de encefalites autoimunes possuem como causa subjacente um câncer, por esse motivo devem todos os pacientes serem submetidos ao rastreio de tumores ${ }^{27}$. Os exames solicitados devem ser a TC de tórax, seguido da FDG-PET se o primeiro for negativo. Para a pelve, a primeira escolha é o USG seguido de TC da pelve. Vale lembrar que os teratomas ovarianos não são vistos na FDG-PET. A síndrome clínica sugere a pista do tumor mais provável, a exemplo do teratoma ovariano na encefalite anti-NMDAr, ou do câncer pulmonar de pequenas células na 
encefalite límbica, com mais detalhes no apêndice 2. Nos pacientes com anticorpos anti-LGI1 e anti-GAD há uma menor incidência de câncer, enquanto que os casos tipicamente paraneoplásicos (ex: anti-NMDAr, anti-CASPR2, anti-AMPAr e anti-GABA-Br), caso 0 primeiro rastreio seja negativo, devem repetir os exames em 3 a 6 meses, seguido de rastreio a cada 6 meses por 4 anos ${ }^{4,21}$.

\subsection{Tratamento}

0 tratamento das encefalites autoimunes consiste de imunossupressão para depletar os autoanticorpos, associado ao manejo oncológico quando necessário (quimioterapia e/ou ressecção tumoral $)^{4}$. A imunossupressão de primeira linha constituise de metilprednisolona endovenosa em $1 \mathrm{~g} /$ dia por 5 dias em adultos, associado a um destes seguintes: imunoglobulina $G$ endovenosa (400 mg/kg/dia por 5 dias) ou plasmaférese (1 vez a cada 2 dias por 10-14 dias). Não há dados comparando a eficácia entre o IVIG e a plasmaférese, ficando à preferência do profissional e sendo o IVIG geralmente usado pela comodidade nos pacientes com discinesias severas, agitação, instabilidade autonômica ou em pacientes pediátricos. A segunda linha é usada nos casos em que não há resposta esperada em 10-14 dias com o primeiro esquema e é feito administrando um ou ambos dos seguintes: rituximab (375 $\mathrm{mg} / \mathrm{m}^{2}$ semanalmente por 4 semanas ou $1 \mathrm{~g}$ em 2 administrações com intervalo de 2 semanas) ou ciclofosfamida $\left(750 \mathrm{mg} / \mathrm{m}^{2}\right.$ semanalmente por 4-6 semanas dependo do resultado) ${ }^{4,21}$. Em crianças, as dosagens dos esquemas de primeira e de segunda linha deve ser adaptada a partir do uso em outras doenças autoimunes (ex: ciclofosfamida no lúpus pediátrico). Nos pacientes já tratados que apresentarem recidiva dos sintomas, a abordagem terapêutica é similar aos casos recém diagnosticados, mas com um limiar menor para iniciar tratamentos de segunda linha no caso de uma recorrência.

$\mathrm{Na}$ Encefalite Anti-LGI1, o tratamento é com glicocorticoides, IVIG, micofenolato mofetil, e/ou plasmaférese. A experiência com rituximab nesses casos é limitada ${ }^{21}$. A encefalopatia de Hashimoto possui um tratamento baseado em levotiroxina associado a corticoesteroides ${ }^{26,28}$. Pacientes com hiponatremia severa complicada e estado de mal epiléptico devem ser tratados agressivamente ${ }^{1}$.

O tratamento precoce está associado a melhor resposta clínica e menores chances de recorrência ${ }^{2,6}$ e, em casos de tratamento antes de caracterizar os autoanticorpos, os testes servirão para decidir entre manter o esquema vigente ou de otimizá102. Não há até 0 momento nenhum protocolo padronizado de tratamento pela falta de pesquisas prospectivas e randomizadas. 0 esquema de tratamento é baseado em estudos observacionais e na experiência clínica com as encefalites anti-NMDAr por ser o tipo mais prevalente e 0 mais estudado ${ }^{14,23}$. Portanto, deve-se individualizar a conduta para cada paciente, considerando a idade, se há a presença de um tumor e a gravidade das manifestações ${ }^{1}$. Também estão relacionados com melhor prognóstico os casos que não necessitam de cuidados intensivos e que não possuem tumor subjacente ${ }^{6}$.

A resposta do tratamento depende do tipo de anticorpo e em geral é satisfatória, uma vez que os autoanticorpos afetam os seus alvos de forma reversível. Anticorpos de superfície neuronal costumam ter prognóstico favorável, enquanto os onconeurais, quase sempre associados a um tumor, possuem prognóstico reservado pela menor resposta à imunoterapia e pelo dano irreversível da resposta T-mediada1,29. A avaliação clínica é soberana ao avaliar o sucesso do tratamento, enquanto os títulos dos autoanticorpos podem persistir no sangue ou no LCR $^{29}$. Num estudo retrospectivo de 501 pacientes com encefalite anti-NMDAr, 75 a $80 \%$ dos tratados com imunoterapia escalonada tiveram um bom desfecho clínico. Dos tratados com o esquema de primeira linha, metade melhorou clinicamente nas primeiras quatro semanas e, desses, 97\% tiveram um bom prognóstico dentro de 24 meses. Aqueles sem boa resposta com a primeira linha em 4 semanas beneficiaram-se com o esquema de segunda linha. Entre 15-24\% dos pacientes tiveram recidiva em 2 anos, com maior risco os pacientes sem tumor subjacente, os com um teratoma oculto ou recorrente, e, mais comumente, entre quem não recebeu imunoterapia no quadro inicial. Aproximadamente $6 \%$ dos pacientes evoluem a óbito. Quase todos eles foram tratados com remoção tumoral e imunoterapia como primeira linha, incluindo esteroides, IVIG e/ou plasmaferese ${ }^{14}$.

\section{NOVAS PERSPECTIVAS E CONSIDERAÇÕES FINAIS}

Mesmo com maior conhecimento disponível para manejar as encefalites autoimunes, sua investigação continua requerendo um médico especialista e exames de alta complexidade. Mais pesquisas são fundamentais para aprimorar os métodos diagnósticos, e tornar a investigação mais simples, rápida e acessivel2. Também se questiona outros possíveis fatores desencadeantes, como ambientais ou genéticos ou outras infecções. Levando-se em consideração falta de critérios diagnósticos para pacientes pediátricos e geriátricos, também são necessários mais estudos nessas populações. A baixa prevalência da doença, porém, dificulta os estudos ${ }^{2,23}$. 
1. Lancaster E, Dalmau J. Neuronal autoantigens-pathogenesis, associated disorders and antibody testing. Nat Rev Neurol. 2012;8(7):380-90.

2. Graus F, Titulaer MJ, Balu R, Benseler S, Bien CG, Cellucci T, et al. A clinical approach to diagnosis of autoimmune encephalitis. Lancet Neurol. 2016;15(4):391-404.

3. Granerod J, Ambrose HE, Davies NWS, Clewley JP, Walsh AL, Morgan D, et al. Causes of encephalitis and differences in their clinical presentations in England: A multicentre, population-based prospective study. Lancet Infect Dis. 2010;10(12):835-44.

4. Dutra LA, Abrantes F, Toso FF, Pedroso JL, Barsottini OGP, Hoftberger R. Autoimmune encephalitis: a review of diagnosis and treatment. Arq Neuropsiquiatr. 2018;76(1):41-9.

5. Gaieski DF, O'Brien NF, Hernandez R. Emergency Neurologic Life Support: Meningitis and Encephalitis. Neurocrit Care. 2017;27:12433.

6. $\quad$ Ankersmit HJ, Felipe A De, Saiz A. Encephalitis and GABA B receptor antibodies. Neurology. 2013;81:1-7.

7. Van Coevorden-Hameete MH, de Graaff E, Titulaer MJ, Hoogenraad CC, Sillevis Smitt PAE. Molecular and cellular mechanisms underlying anti-neuronal antibody mediated disorders of the central nervous system. Autoimmun Rev. 2014;13(3):299-312.

8. Linnoila JJ, Binnicker MJ, Majed M, Klein CJ, McKeon A. CSF herpes virus and autoantibody profiles in the evaluation of encephalitis. Neurol - Neuroimmunol Neuroinflammation. 2016;3(4):e245.

9. $\quad$ Frank Leypoldt, Klaus-Peter Wandinger, Christian G Bien and JD. Autoimmune Encephalitis HHS. Eur Neurol Rev. 2013;8(1):31-7.

10. Dalmau J, Rosenfeld MR, DeAngelis LM, Eichler AF. Paraneoplastic and autoimmune encephalitis. Uptodate. 2017;(December):1-22.

11. Davis R, Dalmau J. Autoimmunity, seizures, and status epilepticus. Epilepsia. 2013;54(SUPPL. 6):46-9.

12. Nóbrega-Jr AW, Gregory CP, Schlindwein-Zanini R, Neves F de S, Wolf $P$, Walz R, et al. Mesial temporal lobe epilepsy with hippocampal sclerosis is infrequently associated with neuronal autoantibodies. Epilepsia. 2018;59(9):e152-6.

13. Kayser MS, Dalmau J. Anti-NMDA receptor encephalitis, autoimmunity, and psychosis. Schizophr Res. 2016;176(1):36-40.

14. Titulaer MJ, McCracken L, Gabilondo I, Armangué T, Glaser C, lizuka T, et al. Treatment and prognostic factors for long-term outcome in patients with anti-NMDA receptor encephalitis: An observational cohort study. Lancet Neurol. 2013;12(2):157-65.

15. Gresa-Arribas N, Planagumà J, Petit-Pedrol M, Kawachi I, Katada S, Glaser CA, et al. Human neurexin-3a antibodies associate with encephalitis and alter synapse development. Neurology. 2016;86(24):2235-42.

16. Dale RC, Merheb V, Pillai S, Wang D, Cantrill L, Murphy TK, et al. Antibodies to surface dopamine-2 receptor in autoimmune movement and psychiatric disorders. Brain. 2012;135(11):3453-68.

17. Fang B, McKeon A, Hinson SR, Kryzer TJ, Pittock SJ, Aksamit AJ, et al. Autoimmune glial fibrillary acidic protein astrocytopathy: A novel meningoencephalomyelitis. JAMA Neurol. 2016;73(11):1297-307.

18. Kelley BP, Patel SC, Marin HL, Corrigan JJ, Mitsias PD, Griffith B. Autoimmune encephalitis: Pathophysiology and imaging review of an overlooked diagnosis. Am J Neuroradiol. 2017;38(6):1070-8.

19. Schmitt SE, Pargeon K, Frechette ES, Hirsch LJ. Extreme delta brush receptor encephalitis. Neurology. 2012;79:1094-100.

20. Lizcano A, Carriço L, Barbosa P, Carvalho MI, Yasuda C, Montenegro MA, et al. EEG and magnetic resonance imaging abnormalities in patients with acute limbic encephalitis. J Epilepsy Clin Neurophysiol. 2011;17(4):133-9.

21. Dubey D, Blackburn K, Greenberg B, Stuve O, Vernino S. Diagnostic and therapeutic strategies for management of autoimmune encephalopathies. Expert Rev Neurother. 2016;16(8):937-49.

22. Forsström B, Bisławska Axnäs B, Rockberg J, Danielsson H, Bohlin A, Uhlen M. Dissecting antibodies with regards to linear and conformational epitopes. PLoS One. 2015;10(3):1-11.

23. Vincent A, Bien CG, Irani SR, Waters P. Autoantibodies associated with diseases of the CNS: New developments and future challenges. Lancet Neurol. 2011;10(8):759-72.

24. Dahm L, Ott C, Steiner J, Stepniak B. Seroprevalence of autoantibodies against brain antigens in health and disease. :1-23.

25. Petit-Pedrol M, Armangue T, Peng X, Bataller L, Cellucci T, Davis R, et al. Encephalitis with refractory seizures, status epilepticus, and antibodies to the GABAAreceptor: A case series, characterisation of the antigen, and analysis of the effects of antibodies. Lancet Neurol. 2014;13(3):276-86.

26. Payer J, Petrovic T, Lisy L, Langer P. Hashimoto encephalopathy: A rare intricate syndrome. Int J Endocrinol Metab. 2012;10(2):50614.

27. Titulaer MJ, Soffietti R, Dalmau J, Gilhus NE, Giometto B, Graus F, et al. Screening for tumours in paraneoplastic syndromes: Report of an EFNS Task Force. Eur J Neurol. 2011;18(1):19-27.

28. Marshall GA, Doyle JJ. Long-Term Treatment of Hashimoto's Encephalopathy. J Neuropsychiatry Clin Neurosci. 2006;18(1):14-20.

29. Prüss H, Dalmau J, Harms L, Höltje M, Ahnert-Hilger G, Borowski K, et al. Retrospective analysis of NMDA receptor antibodies in encephalitis of unknown origin. Neurology. 2010;75(19):1735-9.

30. Bale JF. Virus and Immune-Mediated Encephalitides: Epidemiology, Diagnosis, Treatment, and Prevention. Pediatr Neurol. 2015;53(1):3-12. 


\begin{tabular}{|c|c|}
\hline Doença & Comentários: \\
\hline \multicolumn{2}{|l|}{ Causas Infecciosas } \\
\hline $\begin{array}{ll} & \text { Virais (HSV, HIV, CMV, HHV6, VZV, EBV, arbovirus, } \\
& \text { enterovirus, raiva) } \\
\text { - } & \text { Bacterianas (Ex: Listeria, Bartonella, Micoplasma, Rickettsia) } \\
\text { - } & \text { Espiroquetas (Ex: síflis, Lyme, Leptospirose) } \\
\text { - } & \text { Tuberca (ex: criptococo, coccidiomicose, histoplasmose) } \\
\text { - } & \text { Doença de Creutzfeldt-Jakob } \\
\text { - } & \text { Doença de Whipple } \\
& \text { Encefalopatia séptica }\end{array}$ & $\begin{array}{l}\text { - História de viagem e exposição a doenças contagiosas } \\
\text { - Teste do LCR para: Culturas, esfregaco para BAAR, PCR para HSV 1/2, } \\
\text { CMV, HHV6, EBV e enterovirus; HIV RNA, VDRL, - Anticorpos para Lyme e } \\
\text { arbovirus, PCR para T. whipple, proteina 14-3-3 e tau } \\
\text { - Sorologias para: HIV, Lyme } \\
\text { - PCR salivar do virus da Raiva } \\
\text { - Nota: O PCR do LCR para herpes simples pode ser negativo se realizado no } \\
\text { início do quadro (ex: nas primeiras 24h) e deve ser repetido se ainda houver } \\
\text { suspeita clínica }\end{array}$ \\
\hline \multicolumn{2}{|l|}{ Causas tóxico-metabólicas } \\
\hline $\begin{array}{l}\text { - Drogas ou medicamentos (Alcool, cetamina, fenciclidina - PCP, } \\
\text { organofosforados) }\end{array}$ & $\begin{array}{l}\text { - Exames toxicológicos séricos e da urina } \\
\text { - Considerar: síndrome da encefalopatia posterior reversível, reação } \\
\text { idiossincrática (síndrome neuroléptica maligna) interaçãáo medicamentosa } \\
\text { (síndrome serotoninérgica), síndrome de abstinência }\end{array}$ \\
\hline - Monóxido de carbono & $\begin{array}{l}\text { - Carboxiemoglobina, RM (restrição à difusão nos gânglios basais ou } \\
\text { substância branca) }\end{array}$ \\
\hline - Encefalopatia de Wernicke & $\begin{array}{l}\text { - Abuso de álcool ou déficits de nutrição, disfunção oculomotora, RM } \\
\text { (substância cinza periaquedutal, corpos mamilares, tálamo medial) }\end{array}$ \\
\hline - $\quad$ Síndrome neuroléptica maligna & $\begin{array}{l}\text {-Uso de certos medicamentos (neurolépticos, antieméticos, litio), abstinência } \\
\text { dopaminérgica, creatino-quinase elevada }\end{array}$ \\
\hline \multicolumn{2}{|r|}{ 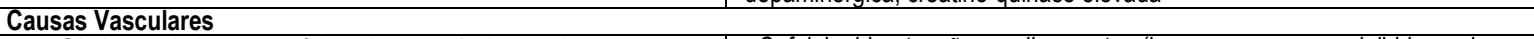 } \\
\hline - $\quad$ Síndrome da leucoencefalopatia reversível posterior & $\begin{array}{l}\text { - Cefaleia, hipertensão, medicamentos (imunossupressores, inibidores de } \\
\text { angiogênese), RM (hiperintensidade em T2 em regiões posteriores ou em } \\
\text { tronco cerebral) }\end{array}$ \\
\hline - Angeíte primária ou secundária do SNC & $\begin{array}{l}\text { - Exames de imagem vascular anormais, ANCA, crioglobulinas, anticorpos } \\
\text { antifosfolipídios }\end{array}$ \\
\hline - Doença de Behçet & $\begin{array}{l}\text { - Ulceras mucocutâneas dolorosas recorrentes, uveíte, teste de patergia } \\
\text { positivo. LCR com pleocitose. Quadro atende aos critérios de Behçet. }\end{array}$ \\
\hline - $\quad$ Síndrome de Susac (Vasculopatia autoimune) & $\begin{array}{l}\text { - Doença rara que pode atender aos critérios de possível encefalite } \\
\text { autoimune. Encefalopatia por trombose microvascular no cérebro, na retina e } \\
\text { no ouvido interno. Apresenta perda auditiva, oclusões dos ramos arteriais da } \\
\text { retina na angiografia fluoresceínica, RM (anormalidades do corpo caloso e da } \\
\text { substância branca periventricular). }\end{array}$ \\
\hline \multicolumn{2}{|r|}{ 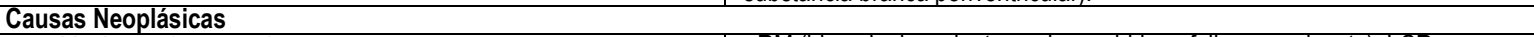 } \\
\hline - Metástase leptomeníngea & $\begin{array}{l}-R M \text { (hipersinal nas leptomeninges, hidrocefalia comunicante), LCR com } \\
\text { citologia }\end{array}$ \\
\hline Glioma difuso & $\begin{array}{l}\text { RM (lesão expansiva com hipersinal em T2), LCR normal } \\
\text { Testes diagnósticos: Biópsia }\end{array}$ \\
\hline Linfoma de SNC primário ou secundário & $\begin{array}{l}\text { - RM (hipersinal no parênquima ou nas leptomeninges), LCR com citologia, } \\
\text { citometria de fluxo e rearranjo do gene lgH }\end{array}$ \\
\hline \multicolumn{2}{|l|}{ Doenças desmielinizantes ou inflamatórias } \\
\hline - Esclerose múltipla & $\begin{array}{l}\text { LCR com bandas oligoclonais (não específicas), lesões neurológicas } \\
\text { características disseminadas em tempo e espaço }\end{array}$ \\
\hline Neuromielite óptica & - Anticorpo NMO \\
\hline Neurossarcoidose & $\begin{array}{l}\text { - Adenopatia hilar ou mudanças do parênquima pulmonar, aumento sérico dos } \\
\text { niveis de ECA }\end{array}$ \\
\hline \multicolumn{2}{|l|}{ Demências neurodegenerativas } \\
\hline - Doença de Alzheimer & \multirow{4}{*}{$\begin{array}{l}\text {-RM (geralmente normal no inicio do quadro, pode demonstrar atrofia focal; } \\
\text { PET/SPECT-TC cerebral com anormalidades regionais }\end{array}$} \\
\hline Demência frontotemporal & \\
\hline Demência de corpos de Lewy & \\
\hline - Demência Vascular & \\
\hline \multicolumn{2}{|l|}{ Doenças psiquiátricas } \\
\hline - Esquizofrenia e outros distúrbios psiquiátricos & \multirow{4}{*}{$\begin{array}{l}\text { - Histórico Familiar } \\
\text { - Sem achados em exames de imagem e de LCR }\end{array}$} \\
\hline Transtorno Bipolar & \\
\hline - Transtorno Conversivo & \\
\hline Doenças metabólicas e hereditárias & \\
\hline - Citopatias mitocondriais & $\begin{array}{l}\text { - Lactato sérico ou do LCR aumentados, pico de lactato na espectroscopia por } \\
\text { RM }\end{array}$ \\
\hline \multicolumn{2}{|l|}{ Outras Doenças: } \\
\hline - Sindromes epilépticas & -EEG, RM \\
\hline $\begin{array}{l}\text { Doenças reumatológicas (lupus, sarcoidose, síndrome de } \\
\text { Sjögren) }\end{array}$ & $\begin{array}{l}\text { - RM com envolvimento unilateral (Sd. De Sjögren) e bilateral (Lúpus) dos } \\
\text { lobos temporais mediais. LCR com pleocitose (Lúpus). Anormalidades } \\
\text { sistêmicas e sorológicas, Critérios para lúpus, Anticorpos SS-A, SS-B, biópsia } \\
\text { de glândulas salivares. } \\
\text { - Sarcoidose: considerar manifestações sistêmicas, pulmonares, } \\
\text { manifiestacóes comuns de neurossarrcoidose (paralisia facial, sinais de lesão } \\
\text { hipofisária). Excluir Tuberculose e Histoplasmose antes de considerar esse } \\
\text { diagnóstic. Hipercalcemia pode ocorrer em metade dos pacientes. A suspeita } \\
\text { indica solicitar hemograma, ECG, TC torácica e avaliar a função renal e } \\
\text { hepática. }\end{array}$ \\
\hline Síndrome de Kleine-Levin & - Hiperfagia, hipersomnia, hiperssexualização \\
\hline - Leucodistrofias & - RM, LCR (podem ter achados semelhantes às encefalites autoimunes) \\
\hline \multicolumn{2}{|c|}{ 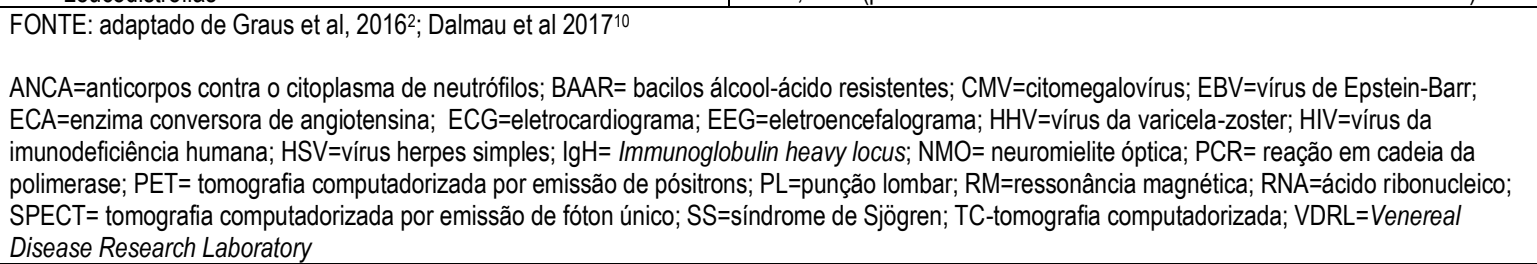 } \\
\hline
\end{tabular}




\begin{tabular}{|c|c|c|c|}
\hline Síndromes & Critérios Diagnósticos & Manifestações Clínicas e Autoanticorpos: & Exames Complementares e Notas: \\
\hline $\begin{array}{l}\text { Encefalite } \\
\text { límbica } \\
\text { autoimune }\end{array}$ & $\begin{array}{l}\text { O diagnóstico de encefalite } \\
\text { autoimune é feito quando atende } \\
\text { os critérios abaixo. A dosagem de } \\
\text { autoanticorpos serve para realizar } \\
\text { o diagnóstico definitivo da doença } \\
\text { específica da encefalite } \\
\text { autoimune. Testes negativos para } \\
\text { autoanticorpos requerem testes } \\
\text { para anticorpos ainda não } \\
\text { descritos em um centro de } \\
\text { pesquisa. } \\
\text { O diagnóstico definitivo é feito ao } \\
\text { satisfazer todos os } 4 \text { abaixo*: } \\
\text { 1. Início subagudo (<3 meses e } \\
\text { rápida progressão) de ao } \\
\text { menos um destes: déficits de } \\
\text { memória de trabalho, } \\
\text { convulsões, ou sintomas } \\
\text { psiquiátricos sugerindo } \\
\text { envolvimento do sistema } \\
\text { límbico } \\
\text { 2. RM com anormalidades } \\
\text { bilaterais restritas aos lobos } \\
\text { temporais mediais, de } \\
\text { anormalidades no T2-FLAIR† } \\
\text { 3. Pelo menos um destes: a) } \\
\text { pleocitose no LCR (>5 } \\
\text { células/mm³); b) EEG com } \\
\text { atividade epiléptica ou de ondas } \\
\text { lentas envolvendo os lobos } \\
\text { temporais } \\
\text { 4. Exclusão adequada de outras } \\
\text { causas } \\
\text { * Se houver testes com a presença } \\
\text { de anticorpos contra superfície } \\
\text { celular, sinápticos ou onconeurais, } \\
\text { pode-se considerar o diagnóstico } \\
\text { definitivo mesmo na falta de um } \\
\text { dos } 3 \text { primeiros itens. } \\
\text { †Para esse critério, pode-se } \\
\text { satisfazer usando FDG-PET, mais } \\
\text { sensível que a TC ao mostrar } \\
\text { aumento da absorção de FDG em } \\
\text { lobos mediais temporais } \\
\text { aparentemente normais. }\end{array}$ & 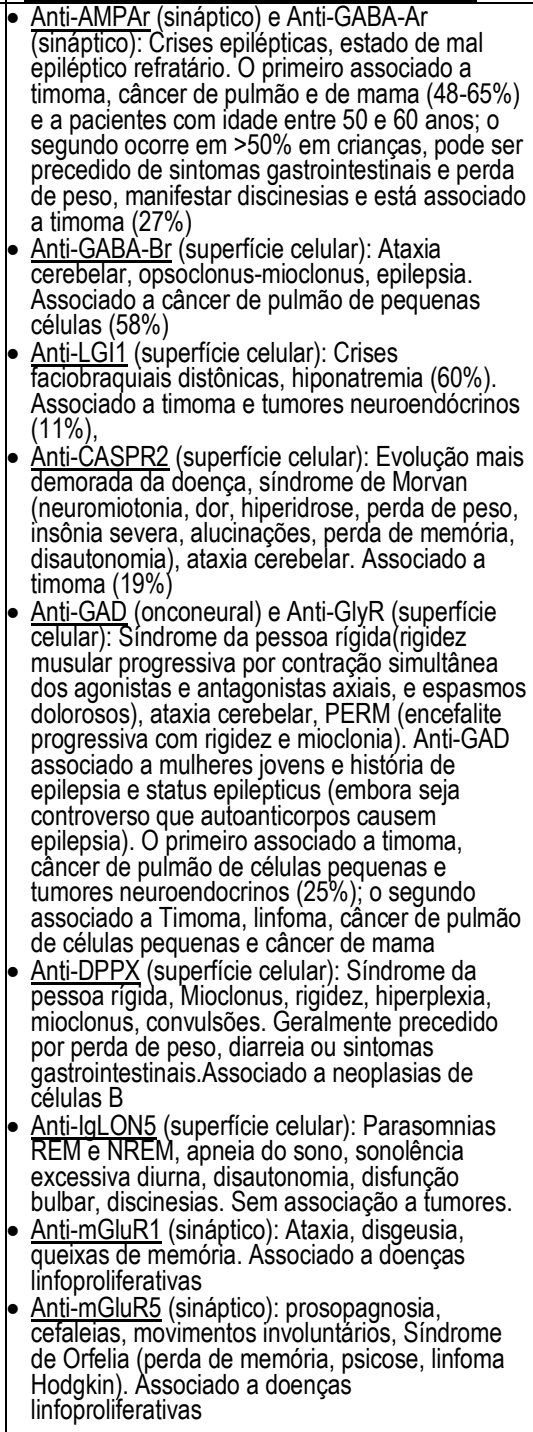 & $\begin{array}{l}\text { LCR: } \\
\text { - 60-80\% com Pleocitose linfocítica } \\
\text { leve-moderada } \\
\text { - } 50 \% \text { com elevado índice IgG ou } \\
\text { bandas oligoclonais. } \\
\text { - Anti-LGI1: Menos comum haver } \\
\text { pleocitose (41\%) e aumento de proteína } \\
\text { (47\%), raramente tem síntese intratecal } \\
\text { de lgG. O LCR pode vir sem sinais pró- } \\
\text { linflamatórios. } \\
\text { RM: } \\
\text { - Geralmente com aumento do sinal T2- } \\
\text { FLAIR na porção medial dos lobos } \\
\text { temporais. } \\
\text { - Anti-GABA-Ar com anormalidades } \\
\text { multifocais corticais e subcorticais em } \\
\text { FLAIR e T2 } \\
\text { - Envolvimento unilateral (ou normal) } \\
\text { não é critério diagnóstico, (pode ser } \\
\text { HSV gliomas, convulsões), } 0 \\
\text { diagnóstico nesses casos é na } \\
\text { presença dos autoanticorpos } \\
\text { - A RM de imunocomprome-tidos com } \\
\text { encefalite por HSV-6 é semelhante à } \\
\text { encefalite límbica autoimune, mas as } \\
\text { manifestações não. Pelo contrário, os } \\
\text { achados de imagem na encefalite por } \\
\text { HSV não são confinados ao sistema } \\
\text { límbico, pode haver características } \\
\text { hemorrágicas, de difusão restrita e } \\
\text { realce por contraste. } \\
\text { - Anti-GABA-Br e Anti-AMPAr podem } \\
\text { estar associados a outras doenças } \\
\text { autoimunes como tireoidite e miastenia } \\
\text { - Anti-lgLON5: realizar Video- } \\
\text { Polissonografia para avaliar distúrbios } \\
\text { do sono } \\
\text { - Anti-GAD: presente no soro de 1\% } \\
\text { das pessoas saudáveis, em } 80 \% \text { dos } \\
\text { DM1 e outras endocrinopatias. Indica } \\
\text { encefalite autoimune se: em altas } \\
\text { titulações séricas, } 100-1000 \text { vezes mais } \\
\text { que na DM1; se producã̃o de Anti-GAD } \\
\text { intratecal, ou bandas oligoclonais no } \\
\text { LCR } \\
\text { - Anti-a-1-GlyR: baixos títulos } \\
\text { documentados em casos isolados de } \\
\text { neurite óptica, esclerose múltipla, ataxia } \\
\text { cerebelar sem síndrome da pessoa } \\
\text { rigida ou encefalomielite progressiva } \\
\text { com rigidez e mioclonus. O significado } \\
\text { desses achados ainda não é claro }\end{array}$ \\
\hline $\begin{array}{l}\text { Encefalomielite } \\
\text { aguda } \\
\text { disseminada } \\
\text { (EAD) e outras } \\
\text { síndromes com } \\
\text { desmieliniza-ção } \\
\text { na RM }\end{array}$ & $\begin{array}{l}\text { O diagnóstico definitivo é feito ao } \\
\text { satisfazer todos os } 5 \text { abaixo: } \\
\text { 1. Paciente com um quadro } \\
\text { neurológico novo multifocal, de } \\
\text { causa presumivelmente } \\
\text { inflamatória desmielinizante } \\
\text { 2. Encefalopatia não explicada } \\
\text { pela febre } \\
\text { 3. Achados anormais na RM } \\
\text { - Lesões difusas, largas (>1- } \\
\text { 2cm) e pouco delimitadas } \\
\text { envolvendo } \\
\text { predominantemente a } \\
\text { substância branca } \\
\text { - Em casos raros, lesões } \\
\text { hipointensas da substância } \\
\text { branca em T1 } \\
\text { - Pode haver anormalidades } \\
\text { nas porções profundas da } \\
\text { substância cinzenta (Ex: } \\
\text { tálamo ou gângilos basais) } \\
\text { 4. Sem novos achados na RM } \\
\text { após } 3 \text { meses do início do } \\
\text { quadro } \\
\text { 5. Exclusão adequada de outras } \\
\text { causas }\end{array}$ & $\begin{array}{l}\text { A desmielinização na RM indica uma provável } \\
\text { encefalite autoimune. Quando isso ocorre, exige- } \\
\text { se pesguisa para os anticorpos: } \\
\text { - Anti-MOG (superfície celular), em cerca 50\% } \\
\text { das crianças, e pode aparecer em outras } \\
\text { doenças desmielinizantes. } \\
\text { - AQP4 (superfície celular) } \\
\text { - NMDAr (sináptico) } \\
\text { Quando positivo fazem o diagnóstico definitivo da } \\
\text { doença específica da encefalite autoimune. } \\
\text { Quando esses testes são negativos, pode-se } \\
\text { fazer uso dos critérios de diagnóstico definitivo } \\
\text { da EAD. } \\
\text { Características: } \\
\text { - Doença inflamatória monofásica do SNC } \\
\text { - Ocorre principalmente em crianças e adultos } \\
\text { antes dos } 40 \text { anos } \\
\text { - Pode ser precedido por uma infecção aguda } \\
\text { sistêmica ou vacinação } \\
\text { - Encefalopatia de extensão variada } \\
\text { - Outros sinais neurológicos: paralisia dos } \\
\text { nervos cranianos, ataxia, hemiparesia, } \\
\text { mielopatia ou neurite óptica. } \\
\text { - Em crianças, deve haver ausência de novos } \\
\text { achados clínicos ou da RM } 3 \text { meses depois do } \\
\text { início do quadro } \\
\text { Anticorpos: } \\
\text { Pode haver sobreposição da encefalomielite com } \\
\text { a encefalite anti-NMDÁr (Ver Encefalite anti- } \\
\text { NDMAr) }\end{array}$ & $\begin{array}{l}\text { LCR: } \\
\text { - Tipicamente com pleocitose leve } \\
\text { (menos de } 50 \text { linfócitos por mm3) } \\
\text { - Incomumente há bandas oligoclonais } \\
\text { (menos de } 7 \% \text { dos casos). } \\
\text { RM: } \\
\text { - Anormalidades em T2-FLAIR múltiplas } \\
\text { e largas (>2cm) que podem estar } \\
\text { presentes na substância branca } \\
\text { supratentorial, gânglios basais, tronco } \\
\text { cerebral, cerebelo e medula espinal, } \\
\text { com ou sem realce por contraste } \\
\text { Fazer diagnóstico diferencial com } \\
\text { síndrome de Susac (apêndice } 1 \text { ) }\end{array}$ \\
\hline $\begin{array}{l}\text { Encefalite anti- } \\
\text { NMDAr }\end{array}$ & $\begin{array}{l}\text { O diagnóstico prováve"* é feito ao } \\
\text { satisfazer todos os } 3 \text { abaixo: } \\
\text { 1. Início rápido (<3 meses) de ao } \\
\text { menos quatro dos seis } \\
\text { sintomas maiores abaixo: } \\
\text { - Comportamento } \\
\text { (psiquiátrico) anormal ou } \\
\text { disfunção cognitiva } \\
\text { - Disfunção da fala: taquilalia, } \\
\text { diminuição da fala, mutismo }\end{array}$ & $\begin{array}{l}\text { - Anticorpo: Apenas o anti-NMDAr (sináptico) } \\
\text { - Quadro clínico compatível } \\
\text { - Comum em < } 45 \text { anos; desses, } 1 / 3 \text { são } \\
\text { menores de } 18 \text { anos, } \\
\text { - Proporção mulher:homem de 4:1 entre 12-45 } \\
\text { anos } \\
\text { Tumor subjacente em > 50\% das mulheres acima } \\
\text { dos } 18 \text { anos (geralmente teratoma de ovário, uni } \\
\text { ou bilateral), e raro em menores de } 12 a \\
\text { (independente do sexo). Também associado a }\end{array}$ & $\begin{array}{l}\text { EEG: } 30 \% \text { dos pacientes apresentam } \\
\text { delta brush extremo, achado específico } \\
\text { da Anti-NMDAr } \\
\text { RM com alterações em } 35 \% \text { dos casos } \\
\text { no início da doença, podendo mostrar } \\
\text { anormalidades tardias em até } 50 \% \text {, } \\
\text { apresentando principalmente lesões } \\
\text { com hipersinal na substância branca e } \\
\text { cinza, podendo em raros casos } \\
\text { apresentar desmielinização. }\end{array}$ \\
\hline
\end{tabular}




\begin{tabular}{|c|c|c|c|}
\hline & $\begin{array}{l}\text { - Crises epilépticas } \\
\text { - Distúrbios do movimento, } \\
\text { discinesias ou } \\
\text { rigidezlposturas anormais } \\
\text { - Diminuicão do nível de } \\
\text { consciência } \\
\text { - Disfunção autonômica ou } \\
\text { hipoventilação central } \\
\text { 2. Pelo menos um dos seguintes } \\
\text { - EEG anormal: atividade } \\
\text { epiléptica, delta brush } \\
\text { extremo, atividade focal, } \\
\text { desorganizada ou difusa } \\
\text { lenta } \\
\text { - LCR com pleocitose ou } \\
\text { bandas oligoclonais } \\
\text { 3. Exclusão adequada de outras } \\
\text { causas } \\
\text { O diagnóstico provável também } \\
\text { pode ser feito com os } 3 \text { acima, se } \\
\text { acompanhado de um teratoma } \\
\text { sistêmico. } \\
\text { O diagnóstico definitivo* é feito na } \\
\text { presença de um ou mais dos seis } \\
\text { sintomas maiores e teste de lgG } \\
\text { anti-GluN1 positivot, após } \\
\text { exclusão adequada de outras } \\
\text { causas: } \\
\text { * Pacientes com história recente } \\
\text { de encefalite por HSV podem estar } \\
\text { sob uma recidiva do quadro na } \\
\text { forma de encefalite autoimune } \\
\text { † Incluindo teste sorológico e do } \\
\text { LCR. Se houver apenas os } \\
\text { resultados sorológicos, realizar } \\
\text { teste de confirmação com } \\
\text { imunohistoquímica. }\end{array}$ & 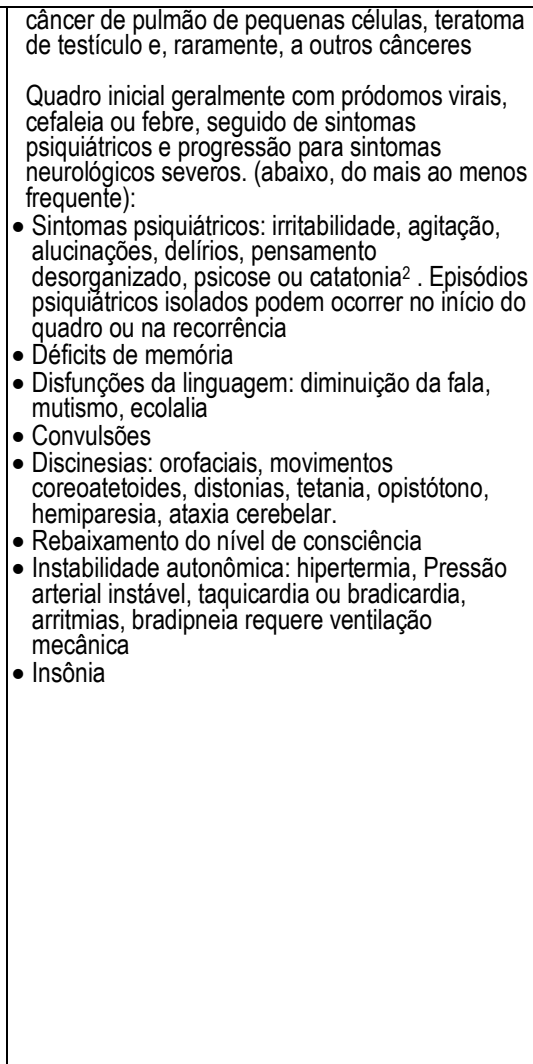 & $\begin{array}{l}\text { Considerar no diagnóstico diferencial: } \\
\text { catatonia maligna, encefalite letárgica, } \\
\text { encefalite viral, dentre outros. } \\
\text { Nos pacientes masculinos, a } \\
\text { associação com tumor é rara, } \\
\text { Pacientes com história recente de } \\
\text { encefalite por HSV desenvolvem, em } \\
20 \% \text { dos casos, uma encefalite } \\
\text { autoimune após semanas ou meses } \\
\text { como recidiva. Nesses casos pode } \\
\text { haver soroconversão do autoanticorpo, } \\
\text { o qual geralmente é anti-NMDA (mais } \\
\text { comum), GABAa ou anti-receptor de } \\
\text { dopamina } 2 \text { (menos comuns). Essa } \\
\text { recidiva se manifesta com sintomas } \\
\text { psiquiátricos ou coreoatetose } \\
\text { (geralmente em crianças). } \\
\text { Sobreposicão de anticorpos de } \\
\text { doencas desmielinizantes com } \\
\text { encefalilte anti-NMDAr: } \\
\text { Em raros casos, pode ocorrer } \\
\text { associado ao quadro de anti-NMDAr as } \\
\text { síndromes MOG- ou AQP4- } \\
\text { relacionadas. Também pode ocorrer de } \\
\text { uma desordem desmielinizante se } \\
\text { apresentar como uma encefalite } \\
\text { autoimune. } \\
\text { Investiga-se os quadros } \\
\text { desmielinizantes com manifestações } \\
\text { atípicas (discinesias ou manifestações } \\
\text { psiquiátricas proeminentes) ou quadros } \\
\text { anti--NMDA atípicos (neurite óptica ou } \\
\text { desmielinização na RM). Solicita-se } \\
\text { teste de anticorpos anti-AQP4 e MOG } \\
\text { no soro (pois a produção intratecal e a } \\
\text { presença desses anticorpos no LCR é } \\
\text { rara) e para receptores anti-NMDA no } \\
\text { soro e no LCR }\end{array}$ \\
\hline $\begin{array}{l}\text { Encefalite do } \\
\text { tronco cerebral } \\
\text { de Bickerstaff }\end{array}$ & $\begin{array}{l}\text { O diagnóstico provável é feito ao } \\
\text { satisfazer todos os } 2 \text { abaixo: } \\
\text { 1. Início subagudo (>4 semanas e } \\
\text { de rápida progressão) de todos } \\
\text { os seguintes sintomas: } \\
\text { - Diminuição do nível de } \\
\text { consciência } \\
\text { - Oftalmoplegia bilateral } \\
\text { externa } \\
\text { - Ataxia } \\
\text { 2. Exclusão adequada de outras } \\
\text { causas } \\
\text { O diagnóstico definitivo é feito na } \\
\text { presença de anticorpos lgG anti- } \\
\text { GQ1b mesmo se não houver } \\
\text { oftalmoplegia bilateral externa ou } \\
\text { se a ataxia não puder ser avaliada, } \\
\text { ou se houver melhora dos } \\
\text { sintomas após } 12 \text { semanas do } \\
\text { início do quadro }\end{array}$ & $\begin{array}{l}\text { - Anticorpo: - IgG anti-GQ1b (superfície celular) } \\
\text { - Doença de curso monofásico, geralmente } \\
\text { precedido de um quadro infeccioso e com bom } \\
\text { prognóstico. } \\
\text { - Sintomas com início subagudo, em menos de } 4 \\
\text { semanas, dos seguintes: comprometimento } \\
\text { progressivo da consciência associado a ataxia, } \\
\text { oftalmoparesia bilateral e anormalidades } \\
\text { pupilares, paralisia bilateral facial, sinal de } \\
\text { Babinski, paralisia bulbar, perda de força dos } \\
\text { membros (semelhante à sindrome de Guillain- } \\
\text { Barré). } \\
\text { Nota: esses anticorpos também ocorrem na } \\
\text { síndrome de Miller-Fisher, levando alguns } \\
\text { autores a agruparem essas doencas sob o termo } \\
\text { "síndrome de GQ1b". Cerca de } 32 \% \text { dos } \\
\text { pacientes podem não ter os autoanticorpos }\end{array}$ & $\begin{array}{l}\text { LCR: } \\
\text {-Pleocitose ocorre em } 45 \% \text { dos } \\
\text { pacientes. } \\
\text { RM: } \\
\text {-Geralmente normal, mas } \\
\text { anormalidades do cérebro em T2- } \\
\text { FLAIR estão presentes em } 23 \% \text { dos } \\
\text { pacientes. } \\
\text { Deve-se considerar no diagnóstico } \\
\text { diferencial a rombencefalite infecciosa } \\
\text { por Listeria, encefalite por enterovirus } \\
71 \text { em crianças, encefalites do tronco } \\
\text { cerebral de causa paraneoplásica ou } \\
\text { pós-infecciosa, Sindrome LLIPPERS } \\
\text { (inflamação linfocítica crônica com } \\
\text { realce perivascular pontino responsiva } \\
\text { aos esteroides), neurosarcoidose e } \\
\text { linfoma primário do SNC }\end{array}$ \\
\hline \multicolumn{4}{|c|}{$\begin{array}{l}\text { FONTE: adaptado de Graus et al, 20162; Dalmau et al } 201710 \\
\text { a-1-GlyR=subunidade alfa-1 do receptor de glicina; AMPAr=receptor de ácido alfa-amino-3-hidroxi-metil-5-4-isoxazolpropiónico; AQP4=aquaporina 4; } \\
\text { CASPR2= proteína associada à contactina 2; DPPX=proteina } 6 \text { tipo dipeptil-dipeptidase; EEG=eletroencefalograma; FDG-PET= tomografia por emissão } \\
\text { de pósitrons com fluoro-deoxiglicose; GQ1b=gangliosídeo GQ1B; GABA-Ar=receptor do ácido gama-aminobutírico A; GABA-Br= receptor do ácido gama- } \\
\text { aminobutírico B; GAD= descarboxilase do ácido glutâmico; HSV=vírus da herpes simples; IgG=imunoglobulina G; IgLON5=membro } 5 \text { da família IgLON; } \\
\text { LCR=líquido cefalorraquidiano;; LGI1=proteína inativada do glioma rica em leucina 1; mGluR1=Receptor metabotrópico de glutamato 1; mGluR5= } \\
\text { Receptor metabotrópico de glutamato 5; MOG=glicoproteina oligodendrocítica da mielina; NMDAr=receptor do N-metil-D-aspartato; NREM=non-rapid eye } \\
\text { movement; REM=rapid eye movement; RM=ressonância magnética; SNC=sistema nervoso central; T2-FLAIR= imagens de recuperação de inversão } \\
\text { atenuada por fluidos em T2; TC=tomografia computadorizada }\end{array}$} \\
\hline
\end{tabular}

